\title{
CHF enhancement in flow boiling system with TSP and boric acid solutions under atmospheric pressure
}

\author{
Juno Lee*, Yong Hoon Jeong, Byungsoo Shin, Soon Heung Chang \\ Korea Advanced Institute of Science and Technology, Gusungdong, Yuseong-gu, Daejeon 305-701, Republic of \\ Korea \\ *Corresponding author: nezads@kaist.ac.kr
}

\section{Introduction}

In several studies, it was demonstrated that surfactant affects the heat transfer with the change of fluid property related with bubble formation and behavior due to the decrease of surface tension. G. Hetsroni et al. [1] showed in their experiments with Habon G surfactant that the heat transfer of the boiling process is enhanced considerably by the addition of a small amount of surfactant. It was also experimented by Rozenblit et al. [2] on how flow changes in surfactant solution. It showed that gas bubbles in air-water solution with surfactant are smaller in size but much larger in number than in pure air-water mixture, at all flow regimes. In recent, an experiment was performed by Jeong et al. [4], which was on flow boiling CHF enhancement with TSP surfactant solutions under atmospheric pressure in SS316 circular tube. It was represented that the addition of TSP surfactant helps to increase wettability by reducing surface tension and the increment is vary with the concentration of TSP, mass flux, and subcooling.

Tri-sodium phosphate (TSP, $\mathrm{Na}_{3} \mathrm{PO}_{4} \cdot 12 \mathrm{H}_{2} \mathrm{O}$ ) and boric acid $\left(\mathrm{H}_{3} \mathrm{BO}_{3}\right)$ are used in nuclear power plant for maintaining high $\mathrm{pH}$ level during accidents. It is noticed that boric acid concentration is about $2000 \mathrm{ppm}$ at normal condition and about 4000 ppm in IRWST.

In this study, the variation of the CHF is observed in water with TSP or boric acid at circular tube of flow boiling water system under atmospheric pressure. Same procedure of the experiment is performed on several concentrations of TSP or boric acid, and it was shown that TSP and boric acid are effective for the CHF enhancement from the results of the experiment.

\section{Methods and Results}

\subsection{Experimental Works}

The flow boiling CHF experiment was performed using the low pressure water CHF test loop at the Korea Advanced Institute of Science and Technology (KAIST). A test section was directly heated using an electrical DC power supply unit.

Thermocouples, pressure transducer, flow transducer, and other instruments were connected to a HP 3852A data acquisition/control unit for data collection and processing.
The test section is a circular tube of SS316 installed vertically in the test loop. In the test section, fluid flows in vertical upward direction. The temperatures of inlet and outlet of the test section were measured by instream T-type sheathed thermocouples, and the pressures of inlet and outlet of the test section were measured by the pressure transducers. Five K-type thermocouples (outer diameter is $1.5 \mathrm{~mm}$ ) were installed at the outer surface of the test section to measure the wall temperature and detect onset of the CHF. The first thermocouple was attached at $5 \mathrm{~mm}$ below the top of the heated tube, and the rest of the thermocouples are installed at $10 \mathrm{~mm}$ intervals.

The experiment was performed in flow boiling system under atmospheric pressure. Mass flux ranged from 100 to $500 \mathrm{~kg} / \mathrm{m}^{2} \mathrm{~s}$ in the experiment. And two inlet temperatures $\left(50^{\circ} \mathrm{C}\right)$ were used. The test condition is shown in Table 1.

Table 1. Test matrix

\begin{tabular}{ll}
\hline Test matrix & \\
\hline Tube geometry & \\
Outer diameter & $12.78 \mathrm{~mm}$ \\
\hline Inner diameter & $10.98 \mathrm{~mm}$ \\
\hline Thickness & $1.8 \mathrm{~mm}$ \\
Heated length & $240 \mathrm{~mm}$ \\
$\begin{array}{l}\text { Vertical upward flow } \\
\text { Pressure }\end{array}$ & $101.3 \mathrm{kPa}(1 \mathrm{~atm})$ \\
Mass flux & $100 \sim 500 \mathrm{~kg} / \mathrm{m}^{2} \mathrm{~s}$ \\
\hline Inlet temperature & $50^{\circ} \mathrm{C}$ \\
\hline
\end{tabular}

In this study, three concentrations $(0.2,0.4,0.6 \%)$ of TSP and four concentrations $(0.2,0.4,0.6,0.8 \%)$ of boric acid were used.

\subsection{Experimental precedure}

The test loop was filled with plain water, TSP solutions, and boric acid solutions. After that, removing non-condensable gas is needed first. While the experiment is performed, the inlet temperature and the mass flow are maintained at desirable level.

Heating power in the test section was gradually increased by slowly increasing the voltage. The heat flux increment is about $20 \mathrm{~kW} / \mathrm{m}^{2}$ near the expected CHF onset point and $50 \mathrm{~kW} / \mathrm{m}^{2}$ in other section. Every time the voltage is increased, it is needed to check the stability of fluid condition of the test loop. It is the CHF onset point that the sudden increase $\left(\sim 70^{\circ} \mathrm{C}\right)$ of wall temperature of the test section happens. When the onset of CHF is observed, switch of the power supply have to be turn off to prevent the test section from breaking 
immediately. The experiments were performed at inlet subcooling temperature of $50^{\circ} \mathrm{C}$ and five mass flux levels $\left(100,200,300,400\right.$, and $\left.500 \mathrm{~kg} / \mathrm{m}^{2} \mathrm{~s}\right)$.

\subsection{Results and Discussion}

In case of TSP, $21.4 \%$ enhancement of CHF was observed at inlet subcooling temperature of $50{ }^{\circ} \mathrm{C}$ and extremely low mass flux $\left(100 \mathrm{~kg} / \mathrm{m}^{2} \mathrm{~s}\right)$. The trend that the CHF enhancement ratio decreases with the increase of mass flux was shown, and except two cases (200, $300 \mathrm{~kg} / \mathrm{m}^{2} \mathrm{~s}$ ), the CHF enhancement ratio decreased with the increasing of concentration. In case of boric acid, $14 \%$ enhancement of CHF was observed at inlet subcooling temperature of $50{ }^{\circ} \mathrm{C}$ and extremely low mass flux $\left(100 \mathrm{~kg} / \mathrm{m}^{2} \mathrm{~s}\right)$.

The main effects of TSP are the decrease of surface tension and the increase of wettability. It is shown in the study of Jeong et al. [3] well. In case of boric acid, it is similar with TSP. From previous contact angle measurement, the effect of boric acid was demonstrated. It is confirmed the contact angle decrease with the increase of concentration of boric acid, that is, boric acid also has the effect which reduces surface tension. But it can be inferred that the effect on the CHF of boric acid is smaller than that of TSP because the decrease rate of boric acid is smaller than that of TSP.

These additives are not affect other properties except surface tension in low concentration $(<1 \%)$, and the increase of wettability and shorter wave length on the interface between liquid and vapor are due to the decrease of surface tension. It is followed by the phenomena like the decrease in bubble diameter, breakup of bubbles and avoidance of bubble coalescence, and the CHF is enhanced. In Figure 1\&2, the enhancement of CHF is shown well.

The effect of surfactant on the CHF depends on the competition of the possibility of instability occurrence and the increase of wettability which are due to the decrease of surface tension. At flow rate of 100 200 $\mathrm{kg} / \mathrm{m}^{2} \mathrm{~s}$, flow regime is annular flow. In this case, the CHF mechanism is liquid film dryout (LFD). It is well known that the dryout in annular flow relates with droplet entrainment and deposition. In this region, the mechanism of the CHF enhancement is not clear yet.

At flow rate of $300 \sim 500 \mathrm{~kg} / \mathrm{m}^{2} \mathrm{~s}$, flow regime is slug flow. The CHF mechanism is departure from nucleate boiling (DNB). In this case, the CHF is occurred by instability of large slug. If the instability is once occurred around the unstable and wavy slugs, and the surface is dried out having no leeway rewetted. Then, the CHF is occurred. Because the reduced surface tension increases the instability the CHF can decreases rather than increase in this region.

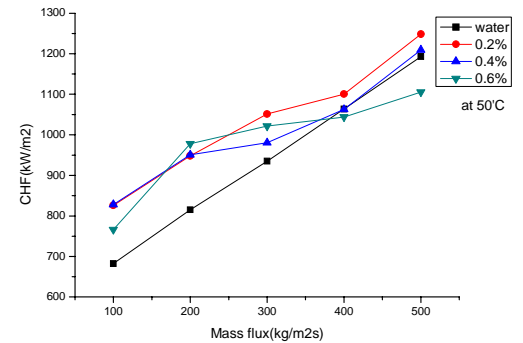

Figure 1. CHF as a function of mass flux for different concentrations of TSP

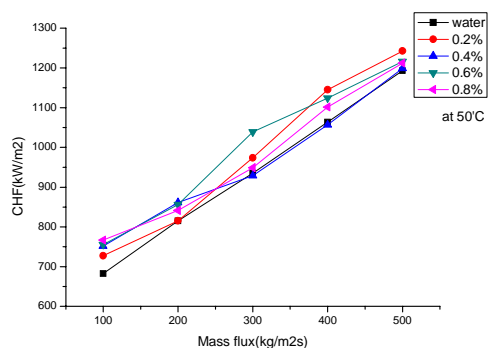

Figure 2. CHF as a function of mass flux for different concentrations of boric acid

\section{Conclusions}

In case of TSP, $21.4 \%$ enhancement of CHF was observed at inlet subcooling temperature of $50^{\circ} \mathrm{C}$ and extremely low mass flux $\left(100 \mathrm{~kg} / \mathrm{m}^{2} \mathrm{~s}\right)$. The trend that the CHF enhancement ratio decreases with the increase of mass flux was shown, and except two cases (200, $300 \mathrm{~kg} / \mathrm{m}^{2} \mathrm{~s}$ ), the CHF enhancement ratio decreased with the increase of concentration. In case of boric acid, $14 \%$ enhancement of CHF was observed at inlet subcooling temperature of $50^{\circ} \mathrm{C}$ and extremely low mass flux $\left(100 \mathrm{~kg} / \mathrm{m}^{2} \mathrm{~s}\right)$. The CHF increasing rate decreased with the increase of mass flux.

\section{REFERENCES}

[1] G. Hetsroni, M. Gurevich, A. Mosyak, R. Rozenblit, Z. Segal, Boiling enhancement with environmentally acceptable surfactants, Int. J. Heat and Fluid Flow 25 (2004) 841-848.

[2] R. Rozenblit, M. Gurevich, Y. Legel, G. Hetsroni, Flow patterns and heat transfer in vertical upward airwater flow with surfactant, Int. J. Multiphase Flow 32 (2006) 889-901.

[3] Yong Hoon Jeong, Won Joon Chang, Soon Heung Chang, Wettability of heated surfaces under pool boiling using surfactant solutions and nano-fluids, Int. J. Heat and Mass Transfer (2007).

[4] S. G. Kandlikar, A theoretical model to predict pool boiling CHF incorporating effects of contact angle and orientation, Int. J. Heat and Mass Transfer 123 (2001) 1071-1079. 